\title{
TUNING SLOCK TOWARDS CHRONIC DISEASE DIAGNOSTICS AND MANAGEMENT: LABEL-FREE SWEAT INTERLEUKIN-31 DETECTION
}

Sayali Upasham ${ }^{\mathrm{a}}$ and Shalini Prasad ${ }^{*}$

AUTHOR ADDRESS: aDepartment of Bioengineering, University of Texas at Dallas, Richardson, TX-75080.

1. SEM image of plain PA membrane

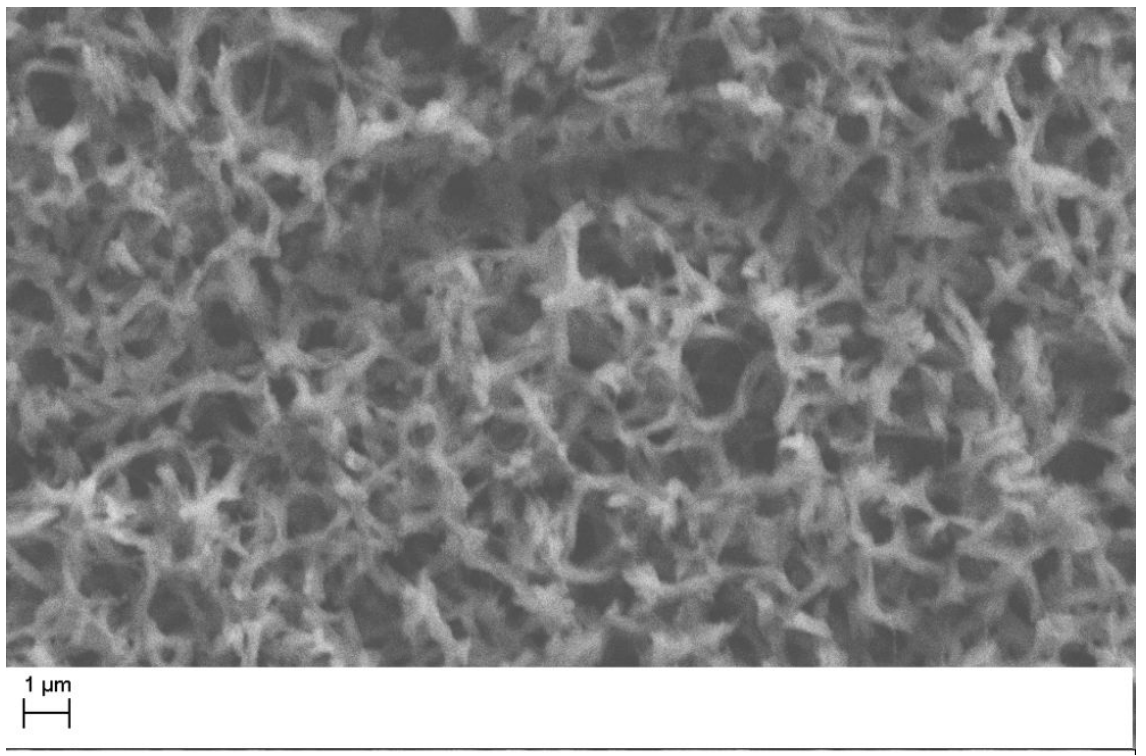

Figure S1: SEM of nanoporous PA membrane

2. Randle's equivalent circuit

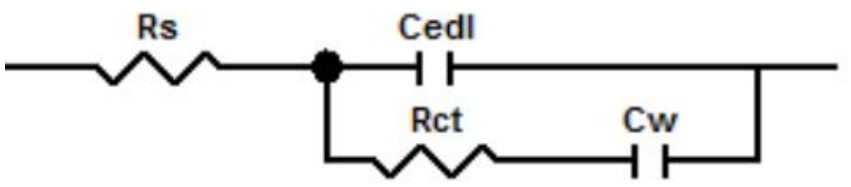

Figure S2: Randle's equivalent circuit for Electrical double layer, Rs: Solution resistance, Cedl: Capacitance of EDL, Rct: Charge transfer Resistance, CW: Warburg Impedance (diffusion) 
3. Nyquist plots

(a)

Nyquist plot for IL-31 in SS pH 4

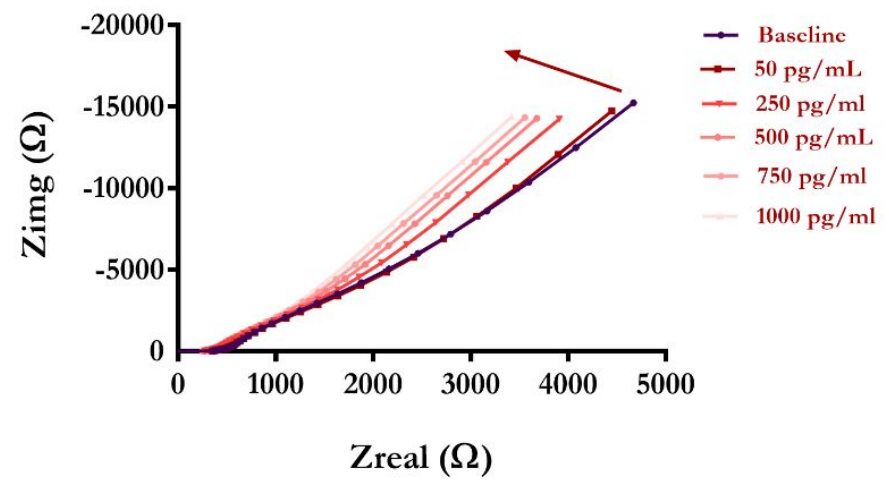

(b)

Nyquist plot for IL-31 in SS pH 6

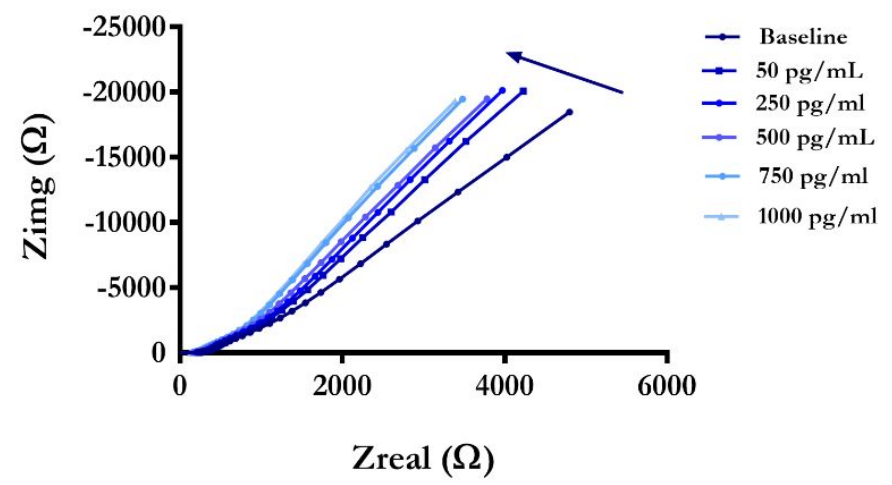

(c)

Nyquist plot for IL-31 in SS pH 8

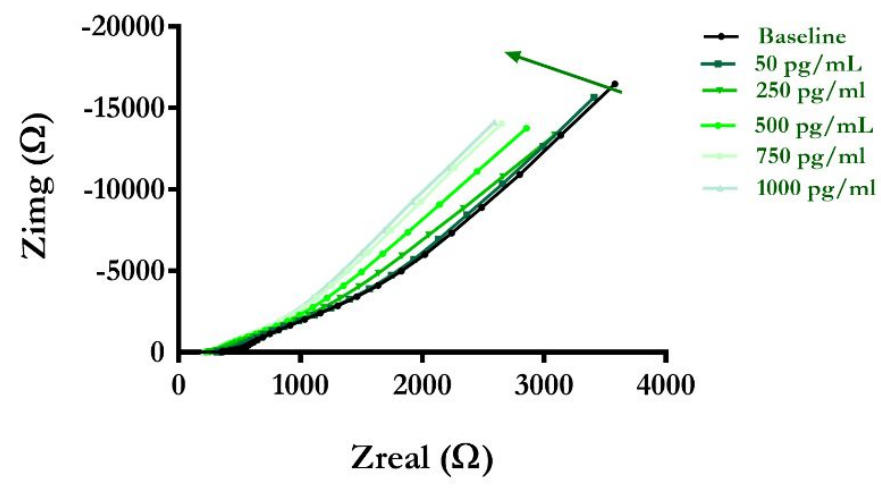

Figure S3: Nyquist plots for CDR in (a) SS pH 4, (b) SS pH 6, and (c) SS pH 8. 


\section{SUPPLEMENTARY DATA}

4. Profilometry data

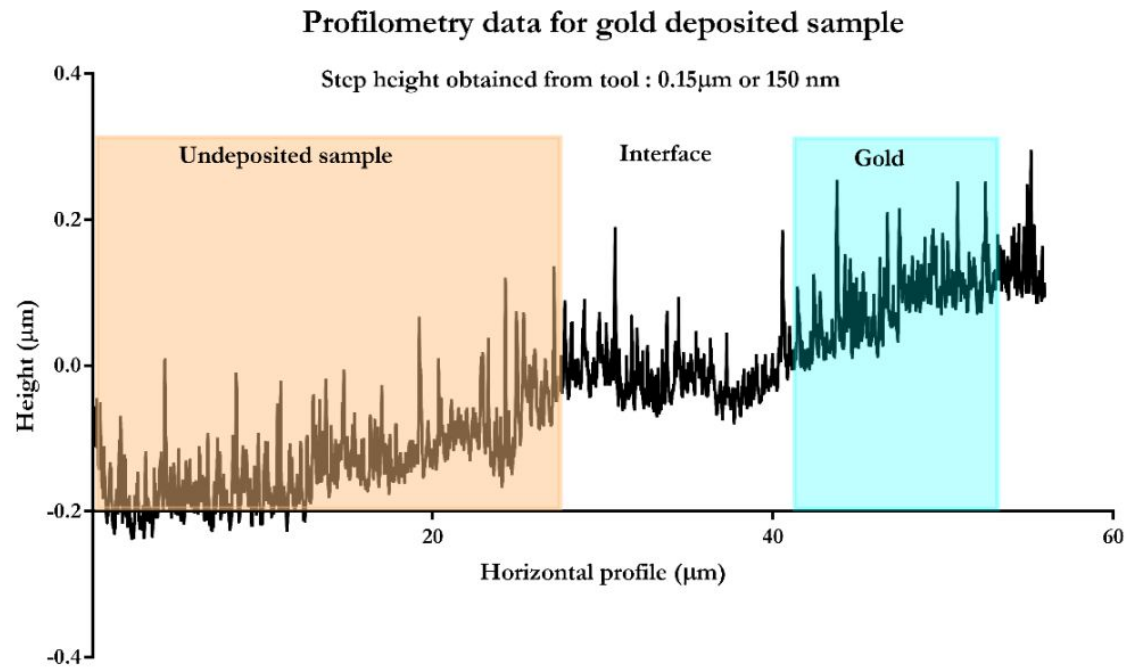

Figure S4: Profilometry highlighting $150 \mathrm{~nm}$ gold deposition 